\title{
Drug Discovery Firms and Business Alliances for Sustainable Innovation
}

\author{
Yoshimi Harada $^{1}$, Huayi Wang ${ }^{1,2}$, Kota Kodama ${ }^{3}$ (D) and Shintaro Sengoku ${ }^{1, *(D)}$ \\ 1 Department of Innovation Science, School of Environment and Society, Tokyo Institute of Technology, \\ Tokyo 108-0023, Japan; harada.y.ao@m.titech.ac.jp (Y.H.); huayiwang59@gmail.com (H.W.) \\ 2 Graduate School of Pharmaceutical Sciences, The University of Tokyo, Tokyo 113-8654, Japan \\ 3 Graduate School of Technology Management, Ritsumeikan University, Kyoto 603-8577, Japan; \\ kkodama@fc.ritsumei.ac.jp \\ * Correspondence: sengoku.s.aa@m.titech.ac.jp; Tel.: +81-3-3454-8907
}

Citation: Harada, Y.; Wang, H.; Kodama, K.; Sengoku, S. Drug Discovery Firms and Business Alliances for Sustainable Innovation. Sustainability 2021, 13, 3599.

https://doi.org/10.3390/su13073599

Academic Editor: Włodzimierz Sroka

Received: 8 February 2021

Accepted: 20 March 2021

Published: 24 March 2021

Publisher's Note: MDPI stays neutral with regard to jurisdictional claims in published maps and institutional affiliations.

Copyright: () 2021 by the authors. Licensee MDPI, Basel, Switzerland. This article is an open access article distributed under the terms and conditions of the Creative Commons Attribution (CC BY) license (https:// creativecommons.org/licenses/by/ $4.0 /)$.
Abstract: Biotech startup firms developing pharmaceutical seeds from scientific and technological innovation are burdened by significant Research \& Development (R\&D) expenses, long-term R\&D operations, and low probability of R\&D success. To address these challenges while sustainably creating innovations and new drugs, business alliances with existing pharmaceutical companies are one of the most important issues on the management agenda. The present study explores the necessity and significance of business alliances with pharmaceutical companies for the development of drug-discovery by Japanese biotech startup firms under high uncertainty. This study investigates the types of alliances to understand the origins of sustainability of these creative activities. First, we investigate and analyze the details of the partnership and its impact on the products under development based on the publicly available information of 16 drug discovery biotech startup firms in Japan that had become public since 2010. As a result, all firms continued their operations with the funds obtained from the business alliances with pharmaceutical firms at the time of their initial public offering (IPO). In addition, $56 \%$ of these firms' alliance projects $(n=73)$ were seeded-out, and $32 \%$ seeded-in, indicating that they had adopted flexible alliance strategies not limited to seedout ones. For sustainable going concern of the biotech startup business, it is valuable to consider multiple strategic options: "in-licensing and value up", "best-in-class", "platform leadership" and "first-in-class" depending on the characteristics of seeds and environmental restrictions.

Keywords: biotechnology; startup; business alliance; drug discovery; research and development; risk management

\section{Introduction}

Innovations in the field of science and technology not only improve products and services providing social and economic value but also contribute to the maintenance and development of human health. The significance of good health and well-being has recently been emphasized in the Sustainable Development Goals (SDGs). The use of drugs is often necessary to maintain good health, therefore, sustainable innovations for diseases without existing treatments or affordable drugs will contribute to SDG 3 as well as other SDGs as it enhances the ability of a community to develop human capital, undertake productive economic activities, and attract investment. For the generation of innovative drugs, biotech startup firms are now becoming crucial in generating promising biomedical products [1]. Biotech startup firms, representing a major change in the technology base of a mature pharmaceutical industry, have appeared to be the solution to a lack of pharmaceutical innovation [2,3]. Biotech startup firms have become the major product innovators in the pharmaceutical industry, and increasing their number is key to stimulating the industry as a whole and contributing to a healthier world. 
In contrast, innovations relying heavily on science and technology often require long R\&D periods, and high levels of resources such as expertise and upfront investment in R\&D costs with a high degree of uncertainty. Therefore, many challenges in the process of product creation and sustainable growth for biotech startup firms with insufficient resources remain. As spelled out in Goal 9 of the SDGs, investment in innovation is a crucial driver of economic growth and development. Furthermore, investment in this area should be fostered but should also be efficient enough to maximize innovation creation with limited resources. However, as mentioned above, drug discovery requires massive investment and a long time to market, which raises problems for the development of more sophisticated business models which achieve higher productivity in R\&D and make it difficult to overcome those inevitable conditions.

To cope with the issues facing drug discovery biotech startup firms, the present study clarifies the significance and necessity of business alliances with pharmaceutical companies for the development of these firms. The differences in significance depend on the types of alliances, and firms' ceaseless efforts to stay relevant while continuing drug discovery activities. Particularly, for biotech startup firms aiming to create the seeds of new drugs, the R\&D burden of the product is large, the development period is long (more than 10 years on average), and the probability of success in bringing the product to market after entering clinical trials is low (less than 10\%) [4].

To investigate these issues, we selected drug discovery-oriented biotech startup firms that had an initial public offering (IPO) in Japan and analyzed the underlying factors for business alliances based on the management and financial conditions at the time of the IPO and in the most recent fiscal year (FY2019). Moreover, we examined the implications of business alliances for the development of drug discovery biotech startup firms by comprehensively extracting, classifying, and analyzing the business alliances of the target firms.

\section{Previous Research}

\subsection{Drug Discovery-Oriented Biotech Startup Firms for Sustainable Innovation}

In product development in the pharmaceutical industry, there has been a remarkable rise of biotech startup firms that develop innovative products in addition to existing pharmaceutical companies. Weisback and Moos (1995) have identified the important role of biotech startup firms in product development in the pharmaceutical industry and biotech startup firms have gained more attention [5]. The number of drugs originating from large pharmaceutical companies is declining, with $67 \%$ of drugs approved by the US Food and Drug Administration (FDA) supported by the top 20 largest pharmaceutical companies in sales in 2013, down to 32\% in 2018 [6]. This number includes several drugs with development originating in drug discovery biotech startup firms; however, they were supported by major pharmaceutical companies through acquisitions or business partnerships before receiving FDA approval. Considering this, the focus of drug development appears to be shifting further to biotech ventures.

In contrast, according to Pisano (2006), only about $20 \%$ of the drug discovery biotech startup firms that went through IPO in the USA in 2004 were able to launch their products, record sales, or receive royalty income from their partner companies. Basically, most drug discovery biotech startup firms are conducting R\&D at a chronic loss [7]. Moreover, a serious uncertainty fundamental to drug discovery research and development causes the low productivity of drug discovery activities. It was highlighted that the average development time is 11.9 years, the $R \& D$ cost per product is $\$ 8-1.3$ billion $[8,9]$, and the probability of success of a product entering clinical development to market is only about $10 \%$ [1], making pharmaceutical product development extremely risky.

According to Deeds and Hill (1996), an "inverse U-shaped" correlation exists between the number of technology alliances and the success rate of new product development in drug discovery biotech startup firms, wherein the rate of new product development increases as the number of technology alliances increases up to a certain size. Therefore, the 
probability of success for drug development were largely influenced by the skills necessary to attract alliances [10]. Hess and Evangelista (2003) investigated the breakdown of funding required in the first 10 years of business in the US pharmaceutical industry and found that venture capital (VC) accounted for only $10 \%$ of funding, while business alliances with major pharmaceutical companies accounted for a large $50 \%$, and the remaining $40 \%$ were through IPO [11].

\subsection{The Importance of Business Alliances}

From a worldwide perspective, Valentine et al. (2003) highlight that in the biotechnologybased pharmaceutical industry, one of the key factors for potential future success is companies' ability to continuously search for and enter business partnerships. They also emphasize that in such companies, the Chief Executive Officer (CEO) and other members of the management team focus on business alliances to ensure the gap is filled between the new products they develop and their commercialization [12]. Liebeskind et al. (1996) suggested that the use of boundary-spanning social networks by the two new biotechnology firms increases both their learning and their flexibility in ways that would not be possible within a self-contained hierarchical organization after examining how two highly successful new biotechnology firms source their scientific knowledge [13]. By extending the Resource-Based View, Lavie (2006) highlighted the competitive advantage of interconnected firms and advanced an ego network perspective [14].

As the cases in Japan are facing severe challenges in industrial sustainability, Ozaki (2004) highlighted the importance of alliances with external organizations in the field of complementary and alternative medicine to increase the probability of success of biotech startup firms [15]. Shindo and Kokubo (2013) quantitatively analyzed cases of technological alliances with biotech startup firms from the perspective of Japanese pharmaceutical companies and found that in the industrial ecosystem of the Japanese biotechnology industry problems were not only caused by industry-academia collaboration policies and financial markets, but instead that Japanese pharmaceutical companies have not fully participated in technological alliances in Japan [16]. Nakamura (2009) provides three reasons for such an ecosystem being established in the biotechnology industry in the USA; however, it is not sufficient in Japan due to the low mobility of R\&D personnel, delay in legal development of industry-academia collaboration, and underdeveloped financial market for startups [17].

As a recent example, Ozaki (2015), based on a survey of representative drug discovery biopharmaceutical companies, highlighted that all companies conducting or preparing to conduct clinical trials, an essential process in drug development, prioritize the prospect of license fee income the most and revealed that they rely on intercompany alliances to generate funds for clinical trials [18].

\subsection{Significance and Benefits of Business Alliance}

As mentioned above, the biotechnology industry is particularly active in business alliance activities [19]; hence, an accumulation of knowledge on business alliances between biotech startup firms and conventional pharmaceutical companies existed.

Besides business alliances, it was highlighted that VCs supported startup firms, especially in the founding phase, not only for financing but also for pragmatic management skills [20]. According to Hellmann and Puri (2002), VCs are instrumental in the evolution of the management teams of their portfolio companies into more professional groups [21]. Another study indicates the importance of VCs for direct strategic guidance and indirect advice through networks for nonfinancial support from VCs [22].

Honjo et al. (2015) found in their study of IPOs and financing of biotech startup firms that VCs are crucial in financing biotech startup firms and that VC investment is seen from the early stage. In contrast, they highlight that the fact that IPOs are seen regardless of market conditions suggests the limits of the investment capacity of Japanese VCs. Therefore, the need for Japanese startup firms, especially biotech startup firms 
requiring large development investments in the early stages to seek funding methods other than VC, has become great [23].

The following is a summary of the significance and utility of business alliances based on representative previous studies.

- Funding Opportunities

Business alliances in R\&D with pharmaceutical companies offer upfront payments, milestones, and royalties in exchange for product patents and marketing rights and are the only or almost only source of income for pre-IPO drug discovery biotech startup firms. Therefore, not only business, but also capital alliances are involved [24].

- Acquisition of knowledge and skills

Smaller startup firms routinely lack the knowledge and capital necessary for bringing their products to market, and, to overcome such shortfalls internally, they actively enter into business-to-business agreements with existing pharmaceutical companies, numbering more than 1000 across the industry [25]. In addition, existing pharmaceutical companies are relatively larger and more experienced and have advantages in, among other things, skills in determining safety and efficacy in clinical trials, expertise in negotiating with the FDA for approval, manufacturing, and marketing and sales. Thus, the probability of success in R\&D has increased. The probability of success in product development through business alliances is high in the later development stages, such as Phase 2 and Phase 3 , and is especially so in cases of alliances with major pharmaceutical companies [26].

Shortening time to market is also an important factor, as venture capitalists and other small and medium-sized companies focus on shortening the R\&D period as much or more than the economic benefits of business collaboration [27].

- Improving corporate reputation and positive influence on the stock market

A biotech startup firm that has formed a business alliance with an existing pharmaceutical company will be perceived as a legitimate company by these pharmaceutical companies, which sends a good signal to the stock market regarding the status of the company's development products and management capabilities. In addition, co-development with pharmaceutical companies is viewed as more likely to succeed than independent development [26].

Although the above is the list of opportunities, there is a study suggesting that a collaboration for one purpose is a beginning of cycle learning. Rather than using external relations as a temporary mechanism to compensate for capabilities a firm has not yet mastered, firms use collaborations to expand all their competencies [28].

\subsection{Issues in Prior Research}

Many discussions have covered the scenario of sustainable development of drug discovery biotech startup firms; however, even in the USA, which is considered to be a developed region, most of the drug discovery biotech startup firms after IPO have been forced to continuously operate at a loss. In Japan, particularly, to conduct clinical trials, which are essential for the development of drugs, business alliances with existing companies are almost an indispensable option due to issues such as insufficient venture capital investment and strict listing conditions for IPO. However, accumulating research on the significance and benefits of business alliances and measures to achieve them, considering the unique circumstances of Japan, is not necessarily sufficient compared to other regions or industries.

Furthermore, in the Japanese stock market, the listing criteria of the Tokyo Stock Exchange's Market Of The High-growth and Emerging Stocks (Mothers) market requires that drug discovery biotech startup firms have at least two products in development and have established a business alliance with an existing pharmaceutical company in Phase 1 or 2 of clinical trials. Therefore, whether the business alliance was necessary for meeting the listing requirements or whether it was essential for the survival of the company was not clearly understood. 
This study attempts to examine the significance of business alliances in drug discovery biotech startup firms operating in Japan through a comprehensive analysis of alliances, including the significance of business alliances from a financial perspective up to the point of IPO, and how patterns of business alliances can contribute to the development of companies and businesses in the growth story after IPO.

\section{Materials and Methods}

\subsection{The Case}

We investigated Japan's market as a case of a non-US country with a world-class science and technology standard. According to the Office of Pharmaceutical Industry Research, Japan is the third country, after the US and the UK, in terms of drug generation of the top 100 drugs based on sales [29]. Amongst those, the US is by far the largest originators of new drugs, which cannot be translated to others where there is much less liquidity of human resources with required talents and much fewer managerial resources available [30]. To consider the norm of sustainable innovation in pharmaceutical busines in advanced countries outside the US, the case of Japan is suitable in terms of the abovementioned circumstances, its scale and scope of the business, and in particular, its presence as an R\&D engine in the worldwide pharmaceutical business.

In Japan, in the research area of this study, we identified 553 biotech startup firms according to the analysis results as of 2014 [31]. According to a survey by Suzuki (2019), the number of Japanese biotech startup firms confirmed to exist as of April 2019 was 2010 [32]. In addition to the fact that this study focuses on the growth stage after IPO and that only a few examples of companies of Japanese origin that have completed an IPO in overseas markets exist, grasping the current status of companies in the unlisted stage is difficult because they do not sufficiently disclose information on their R\&D, financial status, and products. Therefore, we limited our analysis to drug discovery biotech startup firms that have completed an IPO in the Japanese market and investigated and analyzed the status of management indices and business alliances of these companies at the time of IPO and at present (July 2020). From the perspective of publication of comparable data, $16 \mathrm{drug}$ discovery biotech startup firms that have completed an IPO since 2010 and have maintained their listing to date were included in the study. Euglena, which was listed in December 2012, is excluded as a manufacturer of health food. REPROCELL Inc., which was listed in June 2013, is excluded as a manufacturer of reagent. Human Metabolome Technologies Inc., PhoenixBio Co., Ltd., and CellSource Co., Ltd., which were listed in December 2013, March 2016, and October 2019, respectively, are excluded because their main business is drug development support. UMN Pharma Inc., which was listed in February 2012, was delisted in 2019 due to the TOB by SHIONOGI \& Co., Ltd., and Acucela Inc., which was listed in February 2014, was delisted in 2016 and merged with Kubota Pharmaceutical Holdings Co., Ltd. in a triangular merger. Thus, it still exists as a part of Kubota Pharmaceutical Holdings.

\subsection{Analysis of the Indispensability of Business Alliances}

In the Japanese stock market, the listing criteria of the Tokyo Stock Exchange's Mothers market requires that a company has established a business alliance with an existing pharmaceutical company. In this study, we first confirmed that business alliances are not only a formality for meeting the listing requirements but are also essential for the survival of corporate activities.

For this purpose, we investigated the economic impact of business alliances at the time of IPO for 16 companies in our study. Specifically, based on publicly available information, we investigated the timing of the IPO, the amount of funds raised from the market, and the share of capital structure accounted for by major pharmaceutical companies, etc., and compared this to the annual reports of the most recent Fiscal Year (FY) 2019. We also analyzed the financial impact of business alliances on the management of drug discovery biotech startup firms by qualitatively examining the sources of revenue that make up the 
company. The information was collected mainly from investors' relations reports and prospectuses for initial public offerings, annual reports for FY2019, and public information of each company.

\subsection{Analysis on Business Alliance Projects of 16 Target Companies}

To clarify the significance of business alliances, which is the purpose of this study, we examined the significance of business alliances according to companies' development stages. We analyzed business alliances in the above 16 target companies (drug discovery biotech startup firms listed since 2010). Among the drug discovery biotech startup companies listed in the July 2020 issue of Bio Monthly (Mizuho Securities Co., Ltd., Tokyo, Japan), we compiled the following two patterns based on the alliance status and the list of alliance deals in the product pipeline held by each of the 16 target companies. The deals covered are product related with financial conditions, and therefore do not include academic collaboration or alliance in basic research areas.

3.3.1. Analysis of the Impact of Alliances on Marketed and Pipeline Products in Development Owned by Drug Discovery Biotech Startup Firms

We examined the number of projects in each company's pipeline either developed or marketed (in the case of marketed products) with a partner. For the definition of the number of projects, each product of the same development with different development/marketing regions and different indications was considered a different project. Partnerships with institutions such as universities and hospitals were also considered here as "projects with partners." This is because we believed that even in cases where economic investment is not expected, such as in partnerships with pharmaceutical companies, the benefits of having a public institution comprise part of the research and clinical development can be shared, such as through cost-sharing effects and sharing of knowhow.

\subsubsection{Classification of Business Alliance Patterns}

We analyzed the actual status of the alliances in the targeted drug discovery biotech startup firms. We excluded PeptiDream Corporation, which was one of the target companies in former analyses of the present study and analyzed the remaining 15 companies. This is because the number of partnerships with PeptiDream is extremely large, with 111 projects in progress as of July 2020, and the impact of including PeptiDream in the analysis to compare the overall composition ratio may be excessive, and a risk of misjudging the essential trend of the industry generally exists.

Of the 15 companies' alliance deals, a total of 73 deals were analyzed, including all 69 deals listed in Mizuho Securities' Bio Monthly and four deals related to Gene Techno Science Co., Ltd., and StemRim Inc., based on the securities reports of each company. Based on the results, further analyses were conducted on the covered area and product types.

\section{Results}

\subsection{Financial Analysis}

Table 1 presents the IPO period, the amount of funds raised at the time of listing, and the ratio of large companies in the capital structure (only those with $1 \%$ or more are listed) of the 16 existing drug discovery biotech startup firms that have completed an IPO since 2010. 
Table 1. IPO timing, amount of funds raised, and capital ratios of large companies at IPO.

\begin{tabular}{|c|c|c|c|c|}
\hline & Name of Biotech Startup Firms & IPO Date & Fund Raised (JPY Million) & Shareholders: Large Corporation (Pharmaceutical/Chemical/Medical) \\
\hline 1 & CellSeed Inc. & 10 March & 3041 & Sumitomo Dainippon Pharma Co., Ltd. 3.35\%, Olympus Corporation 3.35\% \\
\hline 2 & RaQualia Pharma Inc. & 11 July & 6400 & Pfizer Japan Inc. $18.76 \%$ \\
\hline 4 & 3-D Matrix, Ltd. & 11 October & 3882 & Fuso Pharmaceutical Industries, Ltd. 3.69\%, Excelsior Medical Co Ltd. 3.69\% \\
\hline 5 & CHIOME Bioscience Inc. & 11 December & 2098 & FUJIREBIO Inc. $2.26 \%$ \\
\hline 6 & Gene Techno Science Co.,Ltd. & 12 November & 1200 & Fuji Pharma Co., Ltd. 2.05\% \\
\hline 7 & MEDRx Co., Ltd. & 13 February & 2680 & KOWA Co., Ltd. $4.02 \%$ \\
\hline 8 & PeptiDream Inc. & 13 June & 7763 & Novartis AG $3.75 \%$ \\
\hline 9 & Oncolys BioPharma Inc. & 13 December & 6638 & Astellas Pharma Inc. 9.37\% \\
\hline 10 & RIBOMIC Inc. & 14 September & 4977 & $\begin{array}{c}\text { Otsuka Pharmaceutical Co., Ltd. } 30.53 \% \text { Zenyaku Kogyo Co., Ltd. } 7.83 \% \text {, } \\
\text { Fujimoto Pharmaceutical Corporation } 2.29 \%\end{array}$ \\
\hline 11 & SanBio Co., Ltd. & 15 April & 13,000 & Sumitomo Dainippon Pharma Co., Ltd. 6.67\%, Teijin Ltd. 6.57\% \\
\hline 12 & HEALIOS K.K. & 15 June & 8363 & Sumitomo Dainippon Pharma Co., Ltd. 4.02\%, Nikon Corporation $1.34 \%$ \\
\hline 14 & Solasia Pharma K.K. & 17 March & 4135 & Meiji Seika Pharma Co., Ltd. 5.25\%, Kyowa Kirin Co., Ltd. 1.37\% \\
\hline 15 & Delta-Fly Pharma & 18 October & 3340 & $\begin{array}{l}\text { Yakult Honsha Co.,Ltd. 11.65\%, Sanyo Chemical Industries, Ltd. 3.99\%, Kyowa } \\
\text { Chemical Industry Co., Ltd. 2.66\%, Fuji Pharma Co., Ltd. } 2.66 \%\end{array}$ \\
\hline 16 & StemRim Inc. & 19 August & 8400 & - \\
\hline
\end{tabular}


The amount of funds raised through IPOs ranged from 1.2 billion yen to 13 billion yen, and, considering that the R\&D cost per product is $\$ 800$ million to $\$ 1.3$ billion [8,9], this suggests that conducting drug development on their own by raising funds from the Japanese stock market alone would be difficult. As for the capital ratio by major companies, 14 out of 16 companies had capital alliances with major companies. Of these, the capital alliance between RIBOMIC Inc. and Otsuka Pharmaceutical Co., Ltd. was particularly large at $30.53 \%$, with Otsuka Pharmaceutical investing 20 billion yen at the time of the capital alliance and receiving regular income from long-term joint development. Pfizer Inc.'s stake in RaQualia Pharma Inc. is also high, at $18.76 \%$, because RaQualia Pharma is a drug discovery biotech startup firm was established as a spin-off from Pfizer's research labs. Yakult Honsha Co., Ltd. had a high stake of $11.65 \%$ of Delta-Fly Pharma, Inc., which went public in October 2018, but it had invested 350 million yen in the company as of April 2013. All other capital alliances were for less than $10 \%$.

The results of these analyses suggest that the amount of investment by major pharmaceutical companies in drug discovery biotech startup firms is often small compared to the costs required for pharmaceutical R\&D.

Next, we investigated the revenue provided by pharmaceutical companies for business alliances. Drug discovery biotech startup firms and pharmaceutical companies form alliance agreements for each product or technology they develop, and the resulting upfront payment to the biotech startup firm, milestone payments upon completion of the development stage, and R\&D contract fees are incorporated into the financial statements as income.

Table 2 shows the revenue figures of the 16 drug discovery biotech startup firms and their products approved and launched and sources of income at the timing of IPO (figures are from the financial year immediately prior to the IPO) and in the most recent year (FY2019). The annual revenue of each company at the time of IPO ranged from 62 million yen at CELL SEED Co. to 1.45 billion yen at SymBio Pharmaceuticals Limited.

Only SymBio Pharmaceuticals generated revenue from medicine they developed. It received approval for TREAKISYM ${ }^{\circledR}$ and began selling through Eisai Co., Ltd., its major revenue source, and thus received milestone income in addition to sales revenue from alliance. Other companies, however, had only little sales of reagents and diagnostic reagents as their own products besides alliance income, and the revenue mostly comprised upfront payments from business alliances, milestone income from the stipulations of alliance agreements, and contract research and development costs.

In this analysis, even in FY2019, in the most recent financial report, the sources of income of the 16 target drug discovery biotech startup firms were almost all alliance-related income, with the exception of two companies without revenue in FY2019: HEALISO K.K. and Delta-Fly Pharma, which both terminated their alliance contracts with partners. Four companies had marketed products in FY2019, and all of the firms increased their revenue from the timing of IPO through alliances: RaQualia Pharma Inc., SymBio Pharmaceuticals, 3-D Matrix, Ltd., and Solasia Pharma K.K. Alliance deals had a significant scale of impact on corporate management regarding the amount of income. This suggests that management support from partners is essential for the development of drug discovery biotech startup firms, both before and after IPO.

Figure 1 compares the operating income of 16 drug discovery biotech startup firms between the time of IPO and fiscal year 2019. At the time of IPO, all 16 firms were in deficit. Moreover, by 2019, the deficit had widened further in 14 of the 16 companies. Two firms whose operation profits improved are as follows: RaQualia Pharmaceutical Co., Ltd., which substantially reduced its deficit to -15 million yen, and PeptiDream Inc., which was the only company in the black, posting a significant operating profit of 3.5 billion yen. 
Table 2. Revenue at IPO and in FY2019 and their revenue sources.

\begin{tabular}{|c|c|c|c|c|}
\hline & \multirow[b]{2}{*}{ Name of Biotech Startup Firms } & \multicolumn{3}{|c|}{ At IPO (FY Prior to IPO) } \\
\hline & & $\begin{array}{l}\text { Revenue (JPY } \\
\text { Million) }\end{array}$ & $\begin{array}{c}\text { Products Approved and Launched } \\
\text { before IPO }\end{array}$ & Major Revenue Sources in Descending Order \\
\hline 1 & CellSeed Inc. & 62 & - & $\begin{array}{c}\text { Tokyo Women's Medical University, Funakoshi, Thermo Fisher Scientific, } \\
\text { Wako Pure Chemical Corporation }\end{array}$ \\
\hline 2 & RaQualia Pharma Inc. & 1187 & - & Aratana Therapeutics, Eli Lilly, Maruishi Pharmaceutical \\
\hline 3 & SymBio Pharmaceuticals Ltd. & 1450 & Treakisym in Japan & Eisai \\
\hline 5 & CHIOME Bioscience Inc. & 463 & - & Chugai Pharmaceutical \\
\hline 6 & Gene Techno Science Co.,Ltd. & 207 & - & NAGASE, SHIONOGI \\
\hline 7 & MEDRx Co., Ltd. & 839 & - & KOWA, KM Transderm \\
\hline 8 & PeptiDream Inc. & 269 & - & Bristol-Myers Squibb, Mitsubishi Tanabe Pharma, Amgen, Pfizer \\
\hline 9 & Oncolys BioPharma Inc. & 396 & - & Bristol-Myers Squibb \\
\hline 10 & RIBOMIC Inc. & 151 & - & Otsuka Pharmaceutical, Zenyaku Kogyo, Fujimoto Pharmaceutical \\
\hline 12 & HEALIOS K.K. & 279 & - & Sumitomo Dainippon Pharma \\
\hline 13 & BrightPath Biotherapeutics Co., Ltd. & 822 & - & FUJIFILM, Taiho Pharmaceutical \\
\hline 14 & Solasia Pharma K.K. & 229 & - & Meiji Seika Pharma, Lee's Pharmaceutical, Kyowa Kirin Industry \\
\hline 15 & Delta-Fly Pharma & 150 & - & Kyowa Chemical Industry, Nippon Shinyaku \\
\hline 16 & StemRim Inc. & 200 & & SHIONOGI \\
\hline
\end{tabular}


Table 2. Cont

\begin{tabular}{|c|c|c|c|c|}
\hline & \multirow[b]{2}{*}{ Name of biotech Startup Firms } & \multicolumn{3}{|r|}{ In FY 2019} \\
\hline & & $\begin{array}{c}\text { Revenue } \\
\text { (JPY Million) }\end{array}$ & $\begin{array}{c}\text { Products Approved and Launched } \\
\text { by } 2020\end{array}$ & Major Revenue Sources in Descending Order \\
\hline 1 & CellSeed Inc. & 275 & - & $\begin{array}{c}\text { Meta Tech (AP), Thermo Fisher Scientific, Funakoshi, Tokyo Women's Medical } \\
\text { University }\end{array}$ \\
\hline 2 & RaQualia Pharma Inc. & 1702 & $\begin{array}{l}\text { Potassium-Competitive Acid } \\
\text { Blocker (P-CAB) in Korea, } 2 \text { animal } \\
\text { health products sold in the US/EU }\end{array}$ & Asahi Kasei Pharma, EA Pharma \\
\hline 4 & 3-D Matrix, Ltd. & 328 & $\begin{array}{l}\text { several Hemostatic agents in EU } \\
\text { and US as device }\end{array}$ & Gettinge Australia, Nicolai Medizintechnik \\
\hline 5 & CHIOME Bioscience Inc. & 447 & - & Chugai Pharmaceutical, ADC STHerapeutics \\
\hline 6 & Gene Techno Science Co., Ltd. & 1021 & - & Fuji Pharma \\
\hline 7 & MEDRx Co., Ltd. & 169 & - & Cipla Technologies, Daiichi Sankyo, Nippon Shinyaku \\
\hline 8 & PeptiDream Inc. & 3500 & - & Merck \& Co, Janssen Pharmaceutical, Santen Pharmaceutical \\
\hline 10 & RIBOMIC Inc. & 7 & - & National Cerebral and Cardiovascular Center, Iwai Chemicals \\
\hline 11 & SanBio Co., Ltd. & 741 & - & Sumitomo Dainippon Pharma Co., Ltd. \\
\hline 12 & HEALIOS K.K. & 0 & - & - \\
\hline 13 & BrightPath Biotherapeutics Co., Ltd. & 155 & - & FUJIFILM, Bristol-Myers Squibb \\
\hline 14 & Solasia Pharma K.K. & 1310 & $\begin{array}{l}\text { Sancuso in China, Episil in China, } \\
\text { Korea, Japan }\end{array}$ & Maruho \\
\hline 15 & Delta-Fly Pharma & 0 & - & - \\
\hline 16 & StemRim Inc. & 100 & - & SHIONOGI \\
\hline
\end{tabular}




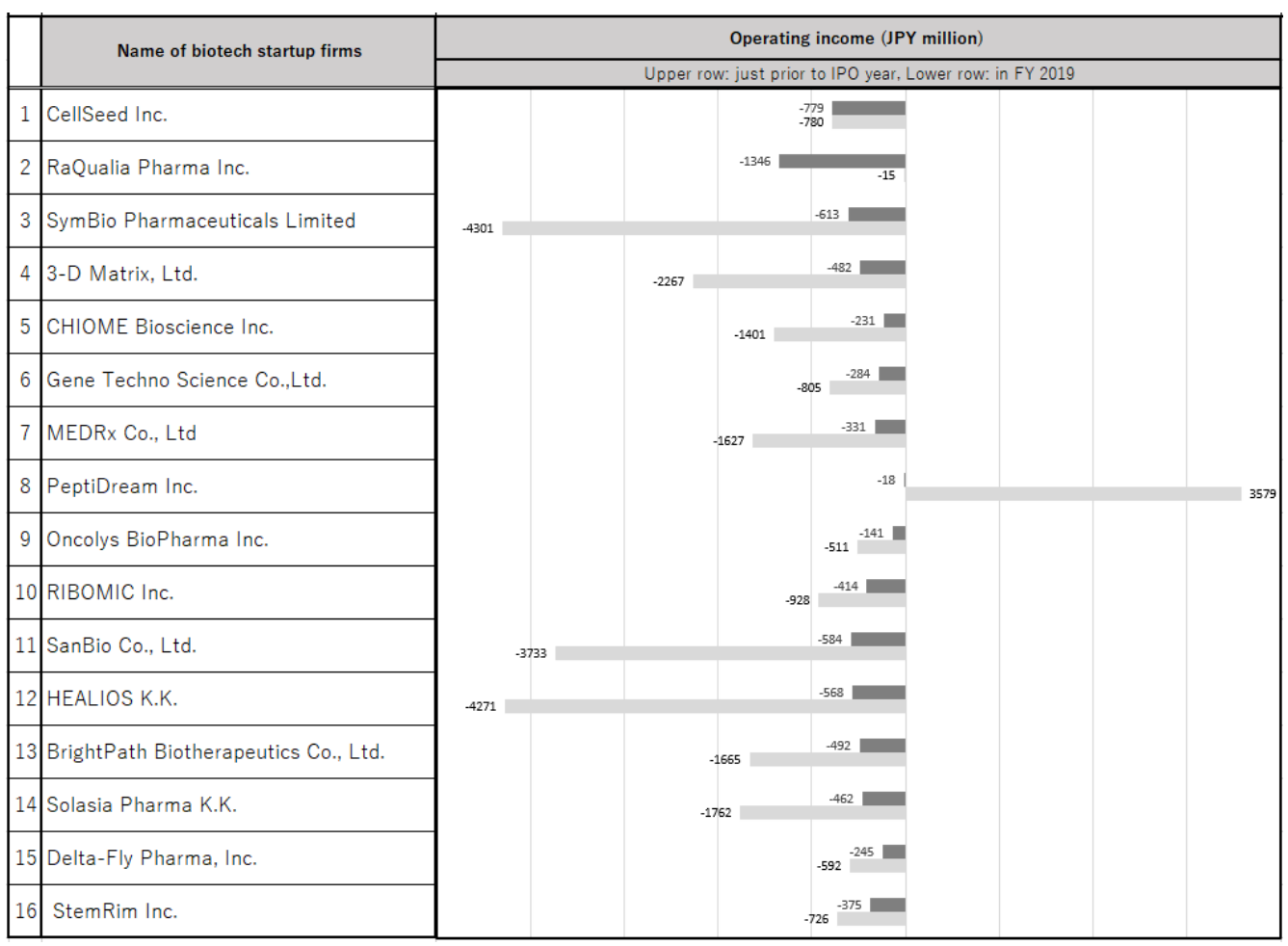

Figure 1. Operating income of drug discovery biotech startup firms.

By 2019, 14 of the 16 had even larger deficits as in Figure 1. One of the reasons for this is that for drug discovery biotech startup firms, which remain mainly engaged in product development and not sales promotion, the cost of clinical development increases as the development phase progresses to the later stages because of the necessity of larger sample sizes with more requirements for efficacy and safety, and the burden becomes greater.

Specifically, SymBio Pharmaceuticals, SanBio Co., Ltd., and HEALIOS K.K., had particularly large deficits. At SymBio Pharmaceuticals, four products were in Phase 3 development in FY2019, and three of which did not have a partner. Similarly, HEALIOS had Phase 2/3 and Phase 2 trials underway in Japan without a development partner. At SanBio, Phase 2 trials for traumatic brain injury were underway in Japan and the US without a development partner, and the development burden was increasing for each company.

In contrast, PeptiDream is the only one of the 16 companies to post a profit in FY2019 with a large operating profit of 3579 million yen. According to the company's FY2019 annual report, most of the company's revenue came from licensing Peptide Discovery Translation System (PDPS) technology, a drug discovery and development platform system, at the request of joint R\&D partners [33].

There are cases, such as HEALIOS, which has raised funds and kept its business alive even when it did not receive income from the alliance on occasion. Although the company had no income in 2018 and 2019 due to a change in the agreement with its partner Dainippon Sumitomo Pharma Co., Ltd. It raised 3.985 billion yen by allocating unsecured convertible bonds with stock acquisition rights to its partner, Nikon Corporation. Moreover, it raised 7.681 billion yen by issuing new shares through overseas offerings and convertible bonds with acquisition conditions due 2020, denominated in Euro yen.

\subsection{Classifications of Business Alliance Patterns}

To clarify the significance and utility of business alliances according to the stage of corporate development, which is the purpose of present study, we analyzed business alliance deals in 16 target companies (drug discovery biotech startup firms listed since 2010).

Figure 2 shows the number of marketed and developed product projects announced as of the end of June 2020, and the availability of developers/partners for those projects. In 
$197(63.8 \%)$ of the total 309 projects, development/sales partner companies were identified. Although the number of projects and partnered projects by each company varied, only two companies, HEALIOS and BrightPath Biotherapeutics Co., Ltd. had no partnered projects in progress. For HEALIOS, this was because of a change of contract with Dainippon Sumitomo Pharma. And, for BrightPath Biotherapeutics, it was because of the temporary loss of partnership projects due to the impact of a development project with FUJIFILM Corporation that did not show positive results in Phase 3 trials.

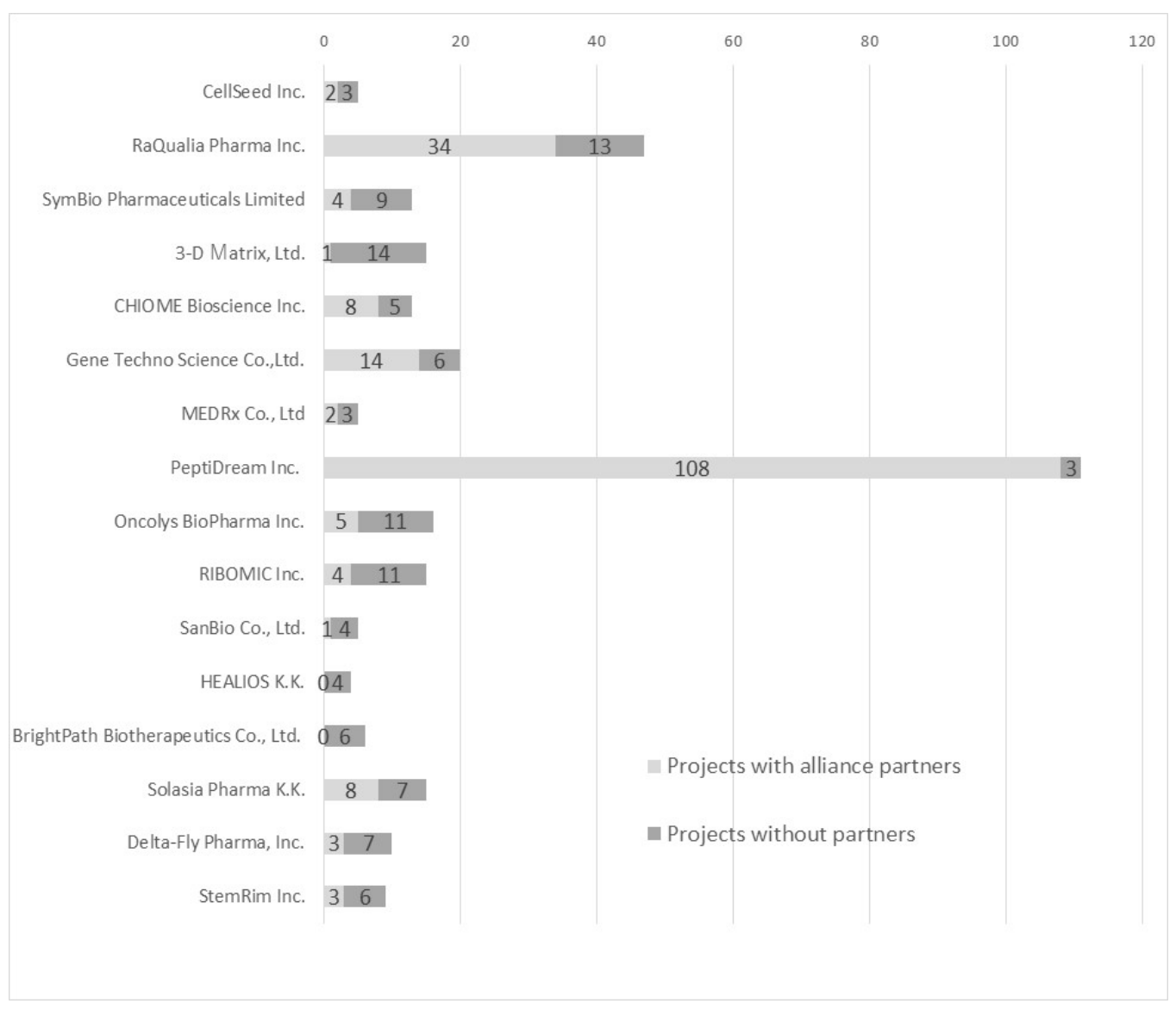

Figure 2. Number of partnerships occupied in development projects as of June 2020.

Even in the case where some projects have "no development partner," such as StemRim and Gene Techno Science, a few projects have been announced or have been classified as "planned collaboration," or "out-licensing activities in progress," suggesting the need for a development/sales partner.

Next, we classified business alliance patterns. We categorized a total of 73 partnerships among the 15 target companies (excluding PeptiDream from the 16 companies) into inlicensing, out-licensing, and other (e.g., granting of option rights and joint development). Therefore, 41 cases (56\%) of out-licensing, 23 cases (32\%) of in-licensing, and 9 cases $(12 \%)$ of others were found. To confirm and understand the reality that in-licensing accounts for $32 \%$ of the alliances in biotech startup firms that create innovations, all 23 cases are summarized in Table 3. 
Table 3. Details of in-licensing alliances with drug discovery biotech startup firms.

\begin{tabular}{|c|c|c|c|}
\hline $\begin{array}{l}\text { Name of Biotech } \\
\text { Startup Firms }\end{array}$ & License Partner & Type of the Products & Date of the Deal \\
\hline SymBio Pharmaceuticals Ltd. & Astellas Pharma GmbH & Small molecule drug & 05 December \\
\hline SymBio Pharmaceuticals Ltd. & Astellas Deutschland GmbH & Small molecule drug & 07 March \\
\hline SymBio Pharmaceuticals Ltd. & Onconova Therapeutics & Small molecule drug & 11 July \\
\hline SymBio Pharmaceuticals Ltd. & The Medicines Company & Small molecule drug & 15 October \\
\hline SymBio Pharmaceuticals Ltd. & Eagle Pharmaceuticals Inc & Small molecule drug & 17 September \\
\hline SymBio Pharmaceuticals Ltd. & Chimerix, Inc. & Small molecule drug & 19 October \\
\hline 3-D Matrix, Ltd. & $\begin{array}{l}\text { Massachusetts Institute of } \\
\text { Technology }\end{array}$ & Peptide (New modality) & 04 October \\
\hline 3-D Matrix, Ltd. & $\begin{array}{l}\text { Becton, Dickinson and } \\
\text { Company }\end{array}$ & Research reagents & 08 February \\
\hline 3-D Matrix, Ltd. & Exploit Technologies PTE LTD & Peptide (New modality) & 14 June \\
\hline CHIOME Bioscience Inc. & Biotecnol Limited & Antibody (New modality) & 18 March \\
\hline Gene Techno Science Co.,Ltd. & Dong-A Pharmaceutical & Production technology & 8 January \\
\hline Oncolys BioPharma Inc. & Stabilitech Biopharma Limited & Stabilizer technology & 18 June \\
\hline Oncolys BioPharma Inc. & $\begin{array}{c}\text { National Institute of } \\
\text { Biomedical Innovation }\end{array}$ & Diagnostics & 11 April \\
\hline Oncolys BioPharma Inc. & Astellas Pharma Inc. & Small molecule drug & 09 October \\
\hline HEALIOS K.K. & Athersys, Inc. & Multistem (New modality) & 16 January \\
\hline HEALIOS K.K. & Athersys, Inc. & Multistem (New modality) & 18 June \\
\hline HEALIOS K.K. & Athersys, Inc. & Multistem (New modality) & 18 June \\
\hline Solasia Pharma K.K. & ProStrakan. Group plc & Small molecule drug & 08 June \\
\hline Solasia Pharma K.K. & Ziopharm Oncology, Inc. & Small molecule drug & 11 March \\
\hline Solasia Pharma K.K. & Ziopharm Oncology, Inc. & Small molecule drug & 14 July \\
\hline Solasia Pharma K.K. & Camurus $\mathrm{AB}$ & Oral fluid (device category) & 15 March \\
\hline Solasia Pharma K.K. & Pled Pharma AB & Small molecule drug & 17 November \\
\hline Solasia Pharma K.K. & Camurus AB & Oral fluid (device category) & 18 August \\
\hline
\end{tabular}

The biotech startup firms implementing in-licensing were found to be unevenly distributed, with 7 out of the 16 companies doing so. As an example, SymBio Pharmaceuticals and Solasia Pharma had almost all of their development products comprised of in-licensed products. As for the types of products to be introduced, "small molecule drug" candidates were the most common, accounting for 11 cases. While some of the products were related to existing products or technology, such as "production technology," "stabilization technology," "reagents," and "diagnostics," only six were introduced as potential sources of breakthrough innovation through new modalities, such as "stem cells," "peptides," and "antibodies".

For out-licensing deals, we conducted further analysis of the target area and types of the target products of alliance deals. Of the 41 out-licensing deals, only 10 were for Japan alone, and 31 were for out-licensing of development and marketing rights overseas, including worldwide, accounting for $76 \%$ of the total ( 8 for worldwide, 17 for the rest of Asia, 5 for North and South America, and 1 for EU). Particularly, the rest of Asian countries consists of more than half of international deals.

The out-licensing deals were categorized by the types of target products and shown in Figure 3. Although nine cases involving new modalities such as peptide vaccines, viral therapies, and regenerative medicine were found, the largest number of cases (11) involved 
small molecule in-licensed products that did not originate from biotech startup seeds. In contrast, there were seven cases of small molecule products which were self-developed and originated from the biotech startup firms. In addition, many cases of out-licensing of products that cannot be called innovation were generated in non-core areas, such as in the surgical field devices (hemostatic agents and other devices), biosimilars, diagnostics, and veterinary drugs.

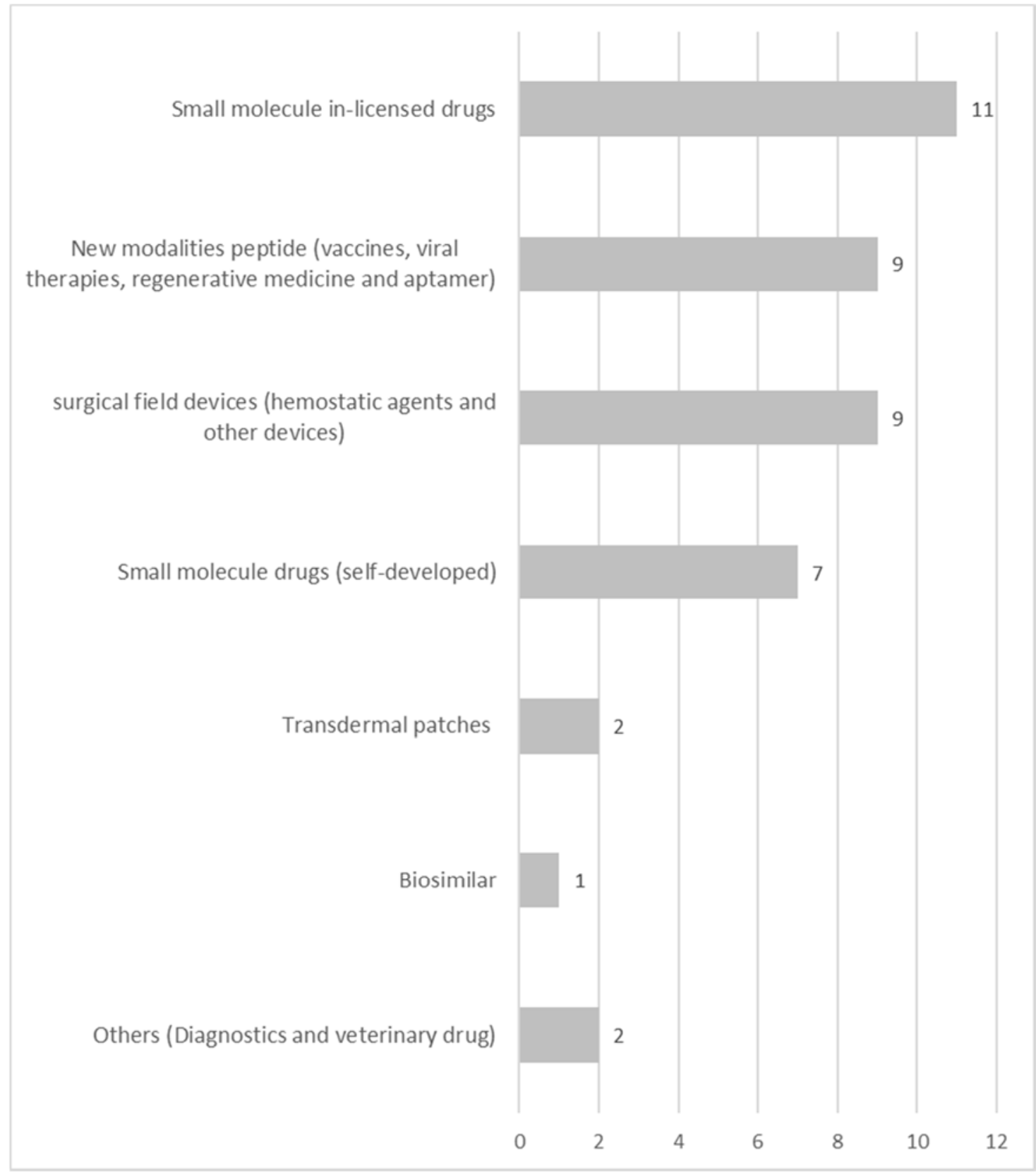

Figure 3. Classification of products to be out-licensed by drug discovery biotech startup firms.

In this study, 73 alliance cases were categorized into in-licensing, out-licensing, and other (e.g., granting of option rights, joint development, etc.), adding a new perspective on the significance and utility of alliances in drug discovery biotech startup firms. The fact that $32 \%$ of the cases were in-licensing cases and most out-licensed products are small molecule in-licensed drugs is noteworthy for drug discovery biotech startup firms that are considered to lead innovation through new drug creation. This suggests that several 
companies have developed from the introduction of existing drug discovery seeds, or that companies that originated from the creation of drug discovery seeds with innovation need to expand their pipelines flexibly to survive as an entity with employees or in case the development of their own drug discovery seeds fails.

\section{Discussion}

\subsection{Business Alliances for Sustainable Innovation}

The number of drug discovery biotech startup firms covered by present study that have completed IPOs since 2010 was only 16. This number of companies, and the fact that the total number of all listed biotech startup firms in Japan is 46 as of the end of July 2020, is an undercount compared to the number of Japanese biotechnology-related startup firms confirmed to exist as of April 2019, which is 2010 [34].

One of the reasons for this is that the IPO requirements in the Japanese stock market may be incompatible for biotech startup firms, including drug discovery companies. For example, the listing criteria for JASDAQ Standard stipulates that ordinary income for the immediately preceding fiscal year should be 100 million yen or market capitalization should be 5 billion yen. This cannot be said to fit the business model of a drug discovery biotech startup firm, which requires large development costs and is in deficit in the early development stage before business value is formed. According to the listing criteria of Tokyo Stock Exchange (TSE) Mothers, a company must have at least two products under development and must have established a business alliance with an existing pharmaceutical company in Phase 1 or 2 of clinical trials [35].

As an example of other countries, in China, where biotech companies are emerging rapidly, 71 and 74 biotech companies completed IPOs in 2017 and 2018, respectively [36]. One of its major markets, the Hong Kong Stock Exchange (HKEX), has similar requirements for clinical trial phases for development-stage products, while not limiting the number of products in development. The NASDAQ in the US is more permissive and allows IPOs without conditions on pipeline products. Particularly, imposing a condition of partnership with an existing pharmaceutical company is a uniquely Japanese characteristic [35]. However, this condition is hypothetically feared to be detrimental to the growth scenario of drug discovery biotech startup firms, which are common internationally, where an IPO is preceded by clinical development to raise funds.

Our analysis on the financial status of the 16 selected companies showed that, with a few exceptions, the revenue of drug discovery biotech startup firms was almost entirely from alliances (Figure 2) and even that revenue could not cover the development costs, and all the companies were in deficit at the time of IPO (Figure 3). The funds raised at IPO ranged from 1.2 billion to 13 billion yen in varying amounts (Table 1); however, considering that the R\&D cost per product is $\$ 800$ million to $\$ 1.3$ billion $[8,9]$, raising funds on the Japanese stock market is not sufficient to conduct drug development on its own. Through our analysis, we confirmed that before business alliances were required as a criterion for IPO in the Japanese market for drug discovery biotech startup firms, alliances with major pharmaceutical companies and other companies were necessary for drug discovery biotech startup firms to survive. The IPO seems to have given the company more credibility in the market and a wider range of fundraising options, making it less dependent on alliance partners. Despite this, a high percentage of development projects that proceed after IPO still have partners (Figure 2), and the trend of companies searching for partners remains evident, suggesting a high need for partnerships even in the post-IPO stage of corporate growth.

\subsection{Types and Significance of Business Alliances}

Among in-licensed small molecule products, a certain type of business alliance exists wherein a new drug with a comparative advantage over existing drugs is developed based on a known mode of action (MOA) and out-licensed to a larger pharmaceutical company responsible for future sales based on the expectation of competitive advantage in the 
market. Basically, this type of business alliance is a case where a "best-in-class" product is licensed out to an existing pharmaceutical company. These new drugs not only improve efficacy and safety profiles but also offer measures such as easier dosing by changing the dosage form, improved medication compliance by reducing the number of doses per day, and improved convenience for physicians by making volume adjustment easier. Recently, products combining multiple types of drugs in a single formulation have become available. Since the development of such a new drug is based on an existing drug or pipeline product that already has gone through proof of concept (POC), whose safety and efficacy have already been established, the cost and uncertainty of development can be reduced and a higher probability of success can be expected compared with the innovative drugs with novel MOA. This category includes combination products wherein multiple existing ingredients are developed as a single product, products in which existing drugs that are already widely used undergo safety improvements, products in which products developed by other companies are introduced and given added value such as expanded indications, and products in which clinical trials at other companies are succeeded and conducted.

For example, SymBio Pharmaceuticals and Solasia Pharma, which only have projects in which the seeds do not originate from the company itself, can be considered to have this type of business model. Basically, such business models are based on products that have already been fully or partially proven to be effective and safe, thus having a higher probability of success to market than breakthrough drugs. This type of project can be suitable for Japanese drug discovery biotech startup firms with high uncertainty risk.

In contrast, in non-small molecule cases, even startup firms that mainly develop their own seeds were in-licensing new modalities such as "peptides," "antibodies," and "stem cells" that could contribute to the development of drug seeds, while in-licensing technologies and diagnostics related to their own seeds, in preparation for the expansion of their pipelines, which relates to a "first-in-class" strategy to challenge for innovative drugs with novel MOA. This study also suggests that the significance and benefits of alliances are not limited to the acquisition of compensation via out-licensing but also include the expansion of the pipeline through in-licensing, the securing of income sources, and risk management as useful strategic options. New drugs with a novel MOA are the source of innovation in the pharmaceutical industry and are expected to have breakthrough efficacy and safety. In fact, as a global trend, most of the innovations in drug discovery are based on new drug development by drug discovery biotech startup firms. In Japan, as shown in Figure 3, many cases of out-licensing have arisen. However, they cannot be said to be innovations that lead to novel drugs, such as the development of small molecule drugs derived from other companies, biosimilars, surgical fields (treated as devices), topical technologies, laboratory drugs, and veterinary drugs. Basically, some of Japan's drug discovery biotech startup firms are playing roles to continue developing pipeline products which were abandoned by major biopharmaceutical companies for various reasons. When developing in-licensing products, improving existing products with same MOA cannot be said to be the driving force behind innovation in the pharmaceutical industry, but it is inevitable for biotech startup firms to continue their operations to achieve their original goals in Japan. Importantly, this tendency is not specific only to Japan: for instance, a study using the entire population of French biotech firms from 1994 to 2002 found that R\&D and funding did not conditionally go together and indicated the difficulty that the French biotech industry also faces to generate scientific innovation while obtaining funds, and balancing the two by taking different types of strategies [36]. Through analysis of data from five U.S. industries over eight years, Yamazaki et al. (2011) propose that in understanding the performance implications of alliance-formation choice, whether the exploration versus exploitation orientation of an alliance portfolio may benefit firm performance depends on how such an orientation fits the firm's internal organizational characteristics, strategic orientations, and the industry environment [37]. There is also a study which suggests that the value of an alliance portfolio depends primarily on the characteristics of partners that managers seek, and then proceeds by examining the important distinction between 
value-creation and value-capture strategies in alliance portfolios. It also proposed that managers consider the best practices for managing alliance portfolios and capturing value from alliances [38]. By sharing such common issues, the present study gives rise to practical solutions for the selection of the four business models.

Regarding target areas of alliance deals, 31 of the 41 out-licensing deals analyzed were for worldwide or non-Japan regions. For biotech companies, the $76 \%$ of out-licensing deals that have the potential for area expansion represent a significant opportunity to leverage existing innovations. In the pharmaceutical industry, drugs with good efficacy and safety profile and are well received in the country where they are launched and tend to be developed and marketed quickly in others. In the pharmaceutical industry, drugs that have good efficacy and safety profile and are well-received in the country where they are launched tend to be developed and marketed quickly in others. Since drug discovery biotech startup firms are small in scale and mainly focus on R\&D, their sales function is weak. Outsourcing the expansion of overseas sales channels to pharmaceutical companies that are excellent at global expansion or have adequate understanding of the industry and market in each country is a reasonable choice in terms of reducing investment risk, focusing on R\&D, and organizational response.

\subsection{Implications for the Pharmaceutical Industry}

We examine the implications of drug discovery biotech startup firms for the pharmaceutical companies with which they are partnering. The number of pharmaceutical companies focusing on business alliances with biotech startup firms has been increasing recently. The characteristics of such companies include the practice of rapid decision-making backed by a high level of expertise and extensive experience, the ability to eliminate bottlenecks in development based on experience, and the willingness to externalize to break away from self-sufficiency [17].

Recently, improving the ability of Japanese pharmaceutical companies to formulate effective business alliances has become necessary. According to a past study, Japanese pharmaceutical companies have received many proposals for business alliances from drug discovery biotech startup firms and are exploring the possibility of such alliances. However, they tended to be hesitant to enter into business alliances due to business profitability issues (low profit margins, insufficient differentiation from competing products, etc.), strategic suitability issues (outside their core therapeutic areas, etc.), and organizational capacity issues (intellectual property management issues, etc.) [39]. While many of these can be attributed to the drug discovery biotech startup firms, they can also be viewed as issues the pharmaceutical industry needs to address more proactively, including self-supporting efforts by the pharmaceutical companies and intermediary efforts by intermediate organizations such as industry associations and regional industry clusters. For successful alliances leading to sustainable innovation, many aspects should be considered between the companies by understanding the fit. There is a study that shows that the most important internal and external variables that explain how knowledge recombination rents arise within a firm's portfolio of inter-organizational relationships. "Internal fit" related to internal contingencies of the firm, specifically life stage and its strategy, and "external fit" related to external contingencies of the network of the firm, specifically previous experience and the current portfolio structure. The knowledge transfer can be increased in a state of a consonance with the overall portfolio and/or with previous experience [40].

\subsection{Limitations and Future Perspectives}

Since this study is based on R\&D information and financial information, it is limited to listed companies considering the availability of such information. In contrast, to examine the significance and benefits of business alliances in the early stages of product development, investigating and analyzing the many unlisted drug discovery biotech startup firms is necessary. In addition, this study is limited to the stock market and drug discovery biopharmaceutical companies in Japan. It is necessary to observe and compare the cases 
of other regions, such as the USA and EU, where many groundbreaking drugs have been produced under the activities of startup firms, and China, where the establishment and listing of startup firms is remarkable.

Figure 4 shows a summary of business alliances of Japanese biotech startup firms. Among the alliances, technology "platform leadership" business alliances, such as the case of Peptidream, have gained prominence, establishing a drug discovery platform based on innovative technology. It leads to competitive advantage, and, by creating a technology platform, revenues can be expected from multiple pharmaceutical companies via outlicensing and joint development. However, we need to keep in mind that these ideal alliance strategy cases are quite rare and dependent on unique and strong technology generation. "First-in-class" business alliances also depend on the innovative pipeline products, whether they are small molecule or new modality, with novel MOA. All the firms using this strategy in this study are making financial loss and continue development supported by alliance partners. Many of them are taking other strategic options such as "best-in-class" or "inlicensing and value-up". As Figure 4 shows, it seems that the case of deriving "best-in-class" products is one of the viable options for portfolio management to reduce business failure risk due to diversification of income loss or failure in the development of existing products, considering the current complexities of the IPO environment in Japan and the difficult business conditions of biotech startup firms where income sources are limited and deficit management is the norm. "In-licensing and value-up" strategy, which involves in-licensing abandoned pipeline products from major pharmaceutical companies, and developing them and out-licensing them, has become a major phenomenon for Japanese biotech startup firms.

\begin{tabular}{|c|c|c|c|}
\hline $\begin{array}{l}\text { Constraints in } \\
\text { human } \\
\text { resource } \\
\text { supply } \\
\text { - High level of } \\
\text { expertise for } \\
\text { innovative } \\
\text { R\&D } \\
\text { - Lack of } \\
\text { talents in } \\
\text { the startup } \\
\text { society }\end{array}$ & $\begin{array}{l}\text { First-in-class strategy } \\
\text { - Self-development of } \\
\text { small molecule/new } \\
\text { modality drugs with } \\
\text { novel mode of actions } \\
\text { and out-licensing }\end{array}$ & $\begin{array}{l}\text { tive advantage over existing } \\
\text { e of action and out-licensing }\end{array}$ & $\begin{array}{l}\text { Constraints in } \\
\text { financial } \\
\text { support } \\
\text { - Sub-scaled } \\
\text { VC } \\
\text { investment } \\
\text { - Highly } \\
\text { volatile } \\
\text { market after } \\
\text { IPO }\end{array}$ \\
\hline
\end{tabular}

\section{Constraints in seed development}

- Long R\&D periods and upfront investment in R\&D costs

- A high degree of uncertainty, low provability of success

Figure 4. Summary of business alliances of Japanese biotech startup firms.

Innovations in the field of science and technology not only improve products and services and provide social and economic value but also contribute to the maintenance and development of human health, which strongly relates to the significance of good health and well-being in SDGs. We hope our study will contribute to solving problems and examining ways to create an environment wherein entrepreneurs who take on the challenge of creating further innovations can actively engage in entrepreneurial activities while accepting a high degree of uncertainty. 


\section{Conclusions}

In this study we discussed the significance and benefits of business alliances with companies to cope with the high uncertainty in startup firms that rely on advanced science and technology. We investigated the case of Japan as a representative of non-US countries to understand the extent of issues caused by this high uncertainty when IPO cannot be the solution like in the US. Most of the drug discovery biotech startup firms that have completed an IPO in Japan have heavily depended on income from business alliances with pharmaceutical companies both before and after their IPO. They also accelerated the development of new products for launch and expanded their sales areas through alliances, confirming that business alliances are an essential requirement for the sustainable activities of these companies. In brief, managers of biotech startups should not be overly concerned with an "one-and-only" innovation model such as the "platform leadership" or "first-in class" approach, but should be flexible in adopting the "best-in-class" or "in-licensing and value-up" strategic option for the survival of business in restricted managerial conditions.

Author Contributions: Conceptualization, Y.H. and S.S.; methodology, Y.H. and H.W.; validation, Y.H.; formal analysis, Y.H.; investigation, Y.H. and S.S.; resources, Y.H. and S.S.; data curation, Y.H. and H.W.; writing — original draft preparation, Y.H.; writing—review and editing, Y.H., K.K. and S.S.; visualization, Y.H.; supervision, K.K. and S.S.; project administration, S.S.; funding acquisition, K.K. and S.S. All authors have read and agreed to the published version of the manuscript.

Funding: This research was supported in part by a Grant-in-Aid for Scientific Research from the Japan Society for the Promotion of Science (grant number: 20H01546).

Institutional Review Board Statement: Not applicable.

Informed Consent Statement: Not applicable.

Data Availability Statement: Mizuho Bio Monthly July 2020 edition issued on 2 July 2020 by Mizuho Securities Co., Ltd. and Disclosed IR information from the website of each company.

Acknowledgments: We thank the members of Sengoku Laboratory, Department of Innovation Science, School of Environment and Society, Tokyo Institute of Technology for providing information and advices. We thank two anonymous reviewers for their contribution to improving the manuscript. Our gratitude is extended to each of the parties listed above.

Conflicts of Interest: Y.H. used to be an employee of Pfizer Japan Inc. and Incyte Biosciences Japan G.K., has no conflicts of interest related to this study.

\section{References}

1. Schuhmacher1, A.; Germann, P.-G.; Trill, H.; Gassman, O. Models for open innovation in thepharmaceutical industry. Drug Discov. Today 2013, 18, 1133-1137. [CrossRef]

2. Drews, J.; Ryser, S. Drug Development: The role of innovation in drug development. Nat. Biotechnol. 1997, 15, 1318-1319. [CrossRef]

3. Fernald, K.D.S.; Weenen, T.C.; Sibley, K.J.; Claassen, E. Limits of Biotechnological Innovation. Technol. Investig. $2013,4,35488$. [CrossRef]

4. Kola, I.; Landis, J. Can the pharmaceutical industry reduce attrition rates? Nat. Rev. Drug Discov. 2004, 3, 711-715. [CrossRef]

5. Weisbach, J.A.; Moos, W.H. Diagnosing the Decline of Major Pharmaceutical Research Laboratories: A Prescription for Drug Companies. Drug Dev. Res. 1995, 34, 243-259. [CrossRef]

6. Dowden, H.; Munro, J. Trends in clinical success rates and therapeutic focus. Nat. Rev. Drug Discov. 2019, 18, 495-496. [CrossRef] [PubMed]

7. Gary, P. Pisano Can Science Be a Business? Lessons from Biotech. Harv. Bus. Rev. 2006, 84, 114-125.

8. Di Masi, J.A.; Grabowsk, H.G. The cost of biopharmaceutical R\&D: Is biotech different? Manag. Decisi. Econ. 2007, $28,469-479$.

9. Drews, J. Innovation deficit revisited: Reflections on the productivity of pharmaceutical R\&D. Drug Discov. Today 1998, 3, 491-494.

10. Deeds, D.L.; Hill, C.W.L. Strategic Alliances and the Rate of New Product Development. J. Bus. Ventur. 1996, 11, 41-55. [CrossRef]

11. Hess, J.; Evangelista, E. Pharma-Biotech Alliances: Jockeying for Position in the Race to Become Partner of Choice. Contract Pharma September 2003. Available online: https:/ / media.gradebuddy.com/documents/2604603/b432be68-d4cc-40fe-8124-1f8 4ff304801.pdf (accessed on 23 March 2021).

12. Valentine, T.; Pickering, A.; Darling, S. Characteristics of eyewitness identification that predict the outcome of real lineups. Cogn. Psychol. 2003, 17, 969-993. [CrossRef] 
13. Liebeskind, J.P.; Oliver, A.L.; Zucker, L.; Brewer, M. Social networks, learning, and flexibility: Sourcing scientific knowledge in new biotechnology firms. Organ. Sci. 1996, 7, 428-443. [CrossRef]

14. Lavie, D. The competitive advantage of interconnected firms: An extension of the resource-based view. Acad. Manag. Rev. 2006, 31, 638-658. [CrossRef]

15. Ozaki, H. Biotech startup firms in the Field of Complementary and Alternative Medicine. J. Jpn. Soc. Complement. Altern. Med. 2004, 1, 103-111.

16. Shindo, H.; Kokubo, K. A Study on Biological Structure in Japanese Bio-industry: From the Perspective of Technology Alliance with Biotech startup firms by Pharmaceutical Manufacturers. J. Creat. 2013, 9, 9-23.

17. Nakamura, Y. Industrial Economic Analysis of Life Science; Keio University Press: Tokyo, Japan, 2009; pp. 96-97, 135-179.

18. Ozaki, H. Growth Strategies of Drug Discovery Biotech startup firms: Differences in Strategies Based on Business Models. Jpn. Soc. Manag. Inform. 2015, 63-78.

19. Roijakkers, N.; Hagedoorn, J.; van Kranenburg, A. Dual market structures and the likelihood of repeated ties-evidence from pharmaceutical biotechnology. Res. Policy 2005, 34, 235-245. [CrossRef]

20. Kobayashi, H. What Makes Ventures Grow Rapidly? 2017 ed.; CHUOKIZAI Publishing: Tokyo, Japan, 2007 ; pp. 87-88.

21. Hellmann, T.; Puri, M. Venture Capital and the Professionalization of Start-Up Firms: Empirical Evidence. J. Financ. 2002, 57, 169-197. [CrossRef]

22. Faber, J.; Castaldi, C.; Muskens, R.W.M. Venture capitalist-induced relational fit and new venture performance: A Dutch biotech comparative case analysis. Venture Capital 2016, 18, 237-256. [CrossRef]

23. Yuji, H.; Nagaoka, S.; Nakamura, K.; Shimizu, Y. Initial Public Offering and Funding of Bio Startups, IIR Working Paper WP315-01 January 2015; Hitotsubashi Innovation Research Center: Tokyo, Japan, 2015.

24. Ö Tulum, W.L. US biopharmaceutical finance and the sustainability of the biotech business model. Res. Policy 2011, 40, 1170-1187.

25. Higgins, M.J. The allocation of control rights in pharmaceutical alliances. J. Corp. Financ. 2007, 13, 58-75. [CrossRef]

26. Nicholson, S.; Danzon, P.M.; McCullough, J.S. Biotech Pharmaceutical Alliances as a Signal of Asset and Firm Quality. J. Bus. 2005, 78, 1433-1464. [CrossRef]

27. McCutchen, W.W., Jr.; Swamidass, P.M. Motivations for strategic alliances in the pharmaceutical/biotech industry: Some new findings. J. High Technol. Manag. Res. 2004, 15, 197-214. [CrossRef]

28. Powell, W.W.; Koput, K.W.; Smith-Doerr, L. Interorganizational Collaboration and the Locus of Innovation: Networks of Learning in Biotechnology. Admin. Sci. Q. 1996, 41, 116-145. [CrossRef]

29. Office of Pharmaceutical Industry Search. Industry Reports No.5; Office of Pharmaceutical Industry Search: Tokyo, Japan, 2014; p. 16. (In Japanese)

30. Wakabayashi, N. The effect of human resource development and economic system in Japanese cluster development—Why Silicon Valley model cannot be transferred? Jpn. Financ. Corp. 2010, 9, 49-70. (In Japanese)

31. Japan Bioindustry Association. 2015 Biotech Startup Statistics and Trends Survey Report; Japan Bioindustry Association: Tokyo, Japan, 2015. (In Japanese)

32. Suzuki, N. Survey and Analysis of the Current Status of Biotechnology-related Ventures in Japan. J. Ind.-Acad.-Gov. Collab. 2019, 15, 15-17.

33. PeptiDream. PeptiDream Corporation Annual Report for the Year; PeptiDream: Kawasaki, Japan, 2019.

34. Biochemical Industry Division of Ministry of Economy, Trade and Industry. Ito Report 2.0 Biomedical Industry; Biochemical Industry Division of Ministry of Economy, Trade and Industry: Tokyo, Japan, 2019. (In Japanese)

35. Deloitte. China 2019 Capital Market Outlook; Deloitte: London, UK, 2019.

36. Durand, R.; Bruyaka, O.; Mangematin, V. Do science and money go together? The case of the French biotech industry. Strateg. Manag. J. 2008, 29, 1281-1299. [CrossRef]

37. Yamakawa, Y.; Yang, H.; Lin, Z.J. Exploration versus exploitation in alliance portfolio: Performance implications of organizational, strategic, and environmental fit. Res. Policy 2011, 40, 287-296. [CrossRef]

38. Lavie, D. Capturing value from alliance portfolios. Organ. Dyn. 2009, 38, 26-36. [CrossRef]

39. Shimokawa, M.; Sekino, K.; Toyoshima, S.; Kobayashi, K. A study on the gap in awareness in alliances between pharmaceutical companies and venture firms. In Research Paper Series No. 65; Pharmaceutical Industry Policy Institute: Tokyo, Japan, 2015; Available online: http://www.jpma.or.jp/opir/research/rs_065/paper_65.pdf (accessed on 3 January 2021). (In Japanese)

40. Pellegrini, M.M.; Caputo, A.; Matthew, L. Knowledge Transfer within relationship portfolios: The Creation of Knowledge Recombination Rents. Bus. Proc. Manag. J. 2019, 25, 202-218. [CrossRef] 